\title{
MRS Medal Awards Go To Meyerson and Sōmiya
}

MRS Medals, which recognize exceptional new discoveries and advances having major impact in a field of materials research, have been awarded this year to two dynamic researchers in two very different areas of materials work. The recipients are:

Dr. Bernard Meyerson, of IBM T.J. Watson Research Center, Yorktown Heights, New York, who is honored "for innovative materials process development leading to fabrication of high speed Si-Ge heterojunction transistors," and

Professor Shigeyuki Sōmiya, of the Nishi Tokyo University, Japan, who is honored "for pioneering research in hydrothermal synthesis of ceramic materials."

The MRS Medals are being presented during the MRS Fall Meeting in Boston, and each recipient has been invited to present a brief paper, to be featured in Symposium X, "Frontiers of Materials Research." Each Medalist will receive an award check, together with an elegantly mounted and engraved Medal.

"An extraordinarily strong set of nominations, representing many different materials fields, presented the Selection Subcommittee with a very difficult task," according to John Baglin, chair of that Subcommittee. "We were greatly impressed with the quality and diversity of the achievements nominated. And we have great confidence that these Medal Awards excellently reflect the ideals of the MRS Medal i rogram."

"We are extremely proud to honor Dr. Meyerson and Professor Somiya with the MRS Medal," said MRS President Jim Roberto. "Both have advanced the materials field with real distinction and critical success, and the MRS feels privileged to recognize their outstanding work in this way."

Meyerson has been the pioneering developer of a process that has extended the applicability of the rather conventional materials (silicon) to electronic devices capable of operating at exceptionally high speeds. The process is low-temperature UHV/ CVD, and it permits the growth of high quality epitaxial silicon and Si-Ge alloy materials, with sharp interfaces, at relatively low temperatures. This breakthrough enables the CVD epitaxial growth of device structures with abrupt dopant profiles, and it has stimulated something of a revolution in silicon thin film and heterojunction research. It allows, for the first time, the application of advancepd band gap engineering concepts to devices fabricated from silicon. The technique has led to the production of Si-Ge heterojunction de-

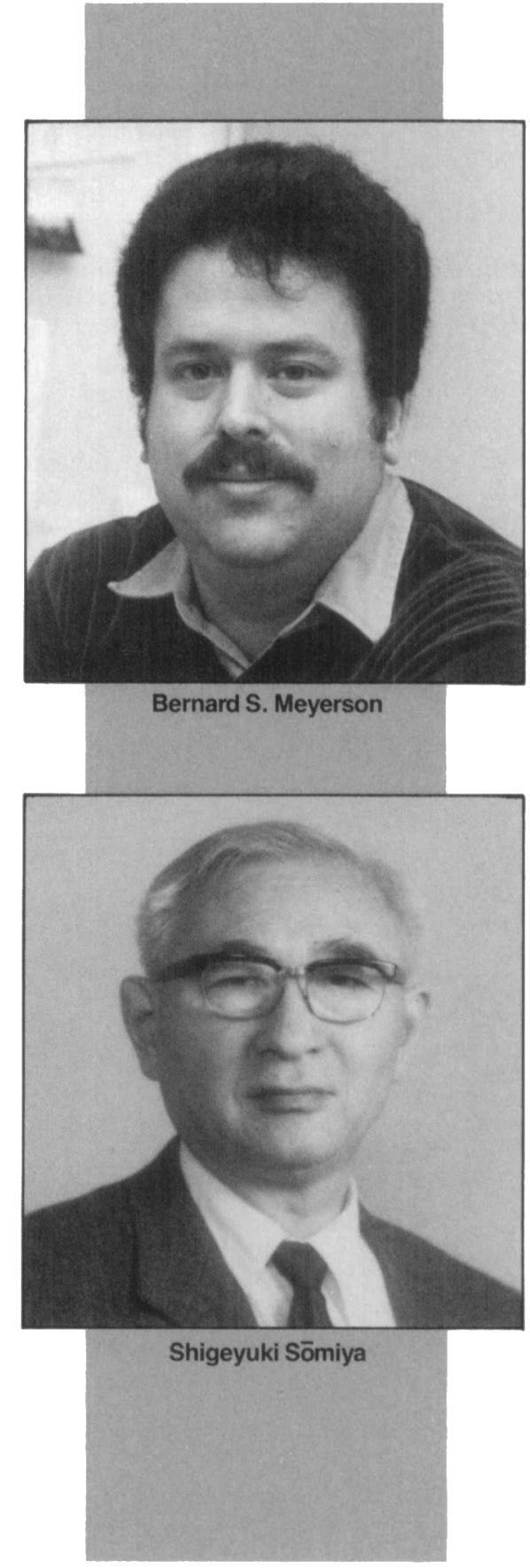

terials engineering and development.

Somiya recognized and developed the unique possibilities for high-temperature/ high-pressure hydrothermal reaction processes in ceramic synthesis, leading to extensive and highly fruitful research programs in the field. Stemming largely from these programs, an entirely new family of ceramic synthesis technologies has emerged. In particular, the very fine (1-100 $\mathrm{nm}$ ), well-crystallized ceramic powders so prepared (including $\mathrm{ZrO}_{2}, \mathrm{HfO}_{2}$, mullite, apatite, $\mathrm{BaTiO}_{3}, \mathrm{LiNbO}_{3}$ ) have shown outstanding properties, such as little or no macroscopic agglomeration, narrow size distribution, reproducible composition, easy sinterability and controlled microstructure, making them excellent materials for ceramics. The new process has also enabled Sōmiya to make new and critical phase diagram determinations, and has led to new insights in the field of singlecrystal growth. Evidence for the dynamism and timeliness of his work is to be found in his 400 related publications and the very substantial laboratory dedicated to his study, which he now directs. Evidence is also to be found in the numerous industrial applications of hydrothermal processing now emerging. Most are in Japan, and they include hydrothermal powders, lightweight cements, ceramic knives, dies, bearings, insulators, biomaterials, coatings for engine parts, catalyst systems, and electronic materials.

J. Murray Gibson, chair of the MRS Awards Committee, added his enthusiastic congratulations to the 1991 winners. He went on to note that nominations for the 1992 Medal will be accepted up to July 1. 1992, and that carefully prepared nominations are important in order to properly represent a nominee's work. "We've been delighted with the number of competitive nominations for this award," he said.

Murray emphasized that the MRS Medal is intended to recognize a specific, defined accomplishment, as contrasted with other kinds of awards designed to recognize broad career achievements. For MRS Medal nominators, it is critically important to explicitly define the accomplishment or discovery for which recognition is proposed, in addition to providing the evidence to support the claim to distinction. A description of the MRS Medal Award, its goals, and nomination requirements is available from MRS Headquarters. Contact: Materials Research Society, MRS Medals Award-B, 9800 McKnight Road, Pittsburgh, PA 15237; phone (412) 367-

3003; fax (412) 367-4373. ously reserved for $\mathrm{GaAs}$ and other The announcement of the new high-speed device in March 1990 sent ripples through the technical and business communities, and the technique is expected to have rapid and dramatic impact in semiconductor ma- 